\title{
Is bi-seasonal germination an optimal choice for an ephemeral plant living in a cold desert?
}

\author{
YANG Shanlin $^{1}$, SHI Xiang ${ }^{1}$, WANG Shaoming ${ }^{2 *}$, LIU Jiashu ${ }^{1}$, MENG Fanxiang ${ }^{2}$, PANG \\ Wei $^{1}$ \\ ${ }^{1}$ College of Agriculture, Shihezi University, Shihezi 832011, China; \\ ${ }^{2}$ College of Life Sciences, Shihezi University, Shihezi 832011, China
}

\begin{abstract}
Research on germination strategies has been proposed as a tool for understanding the evolutionary patterns of plant species living in extreme climate conditions. Previous research has concentrated on spring-germinated plants, while there has been little investigation on the ecological significance of ephemeral plants that germinate in both autumn and spring. The biological characteristics and life history strategies of autumn- and spring-germinated plants of Hypecoum erectum L. that belongs to Hypecoum in Papaveraceae family in the southern part of the Gurbantunggut Desert, China, were investigated from 2016 to 2017. Results showed that: (1) the interval from seedling emergence to the end of the life cycle in autumn-germinated plants (202-208 d) was significantly longer than that in spring-germinated plants (53-65 d); (2) the height, crown, principal axis and the number of leaves of autumn-germinated plants were much greater than those of spring-germinated plants; (3) allocation of dry mass to reproduction was $30.24 \%( \pm 2.41 \%)$ and $10.12 \%( \pm 0.68 \%)$ in autumn- and spring-germinated plants, respectively. Autumn-germinated seedlings of $H$. erectum had an advantage in avoiding the competition between annual and perennial herbs that had longer periods of vegetative growth. Spring-germinated seedlings need to ensure the survival of population when only a fewer autumn-germinated seedlings successfully overwinter. In an unpredictable environment, the germination strategy of bet hedging not only utilizes the resources and reduces the competition intensity in offspring, but also ensures the survival of the plant population.
\end{abstract}

Keywords: ephemeral plant; Gurbantunggut Desert; Hypecoum erectum L.; spring-germinated plants; autumn-germinated plants

Citation: YANG Shanlin, SHI Xiang, WANG Shaoming, LIU Jiashu, MENG Fanxiang, PANG Wei. 2019. Is bi-seasonal germination an optimal choice for an ephemeral plant living in a cold desert? Journal of Arid Land, 11(2): 280-291. https://doi.org/10.1007/s40333-019-0001-1

\section{Introduction}

Ephemeral plants are special group of organisms that have either a shorter life cycle or a shorter annual growth period (Went, 1948). This plant group occurs in the desert areas of Central Asia, Western Asia, North Africa, North America, South America, and the Mediterranean coast, but also occurs in temperate deciduous forest of the northern United States, Japan, and Russia (Huang, 2002). Central Asia is one of the main distribution centers of ephemeral plants. In China, most of ephemeral plants are found in cold desert region of Northern Xinjiang, where there is a common

\footnotetext{
*Corresponding author: WANG Shaoming (E-mail: westwild@vip.sina.com)

The first and second authors contributed equally to this work.

Received 2018-04-12; revised 2018-10-15; accepted 2019-01-11

(C) Xinjiang Institute of Ecology and Geography, Chinese Academy of Sciences, Science Press and Springer-Verlag GmbH Germany, part of Springer Nature 2019
} 
steady snowfall in winter and snowmelt in spring in the Junggar Desert (Pan, 1995). At present, ephemeral plants belong to more than 40 families, they make use of beneficial conditions of spring snowmelt, spring precipitation, rising temperature, and wet soil to complete their life cycle in just 2-3 months (Zhang, 2002). In the Junggar Desert, ephemeral plants, which function as pioneers in the early successional stage of desert plant communities, not only successfully settle in open habitats featuring drought, impoverishment, and mobile and semi-mobile dunes or semi-fixed dunes, but also germinate rapidly and grow vigorously during the annual frequent occurrence of sandstorms in the early spring, thereby completing their life cycle (bearing fruits and seeds or with underground storage organs) before the hot-dry climate of summer (Chen et al., 2008). Therefore, ephemeral plants in the desert can exhibit an important ecological value in terms of species diversity, sand fixation, and the population formation and evolution (Wang et al., 2003).

In the last three decades, ephemeral plants have been increasingly recognized as diverse species with important ecological significance, making them the main phylotype for study by scholars. Several research papers and reviews by foreign scholars have focused on the flora distribution and classification (Shreve, 1936), seed ecology (Gutterman, 2000), physiology (Lambrecht et al., 2007), and the pollination ecology (Mccauley et al., 2017) of ephemeral plants. Chinese scholars have carried out a series of studies, which focused on the anatomy (Zhuang and Tian, 1990a, b; Yang, 1991), embryology (Tan et al., 1996a, b), phenology (Ma and Tan, 2007), and the reproductive ecology (Liu and Tan, 2007; Yang, 2016) of ephemeral plants. Since the biodiversity of ephemeral plants is rich, ephemeral plants constitute an important and unique component of desert flora (Wang et al., 2003; Qiu et al., 2007).

Ephemeral plants possess the capabilities of rapid growth, short vegetative period, summer dormancy, cold tolerance, drought and high-temperature resistance, spring rain dependency, all of which are of ecological significance in the process of plant growth and development. However, seed germination strategies of ephemeral plants are heterogeneous. The germination behavior of seeds allows them to germinate in autumn or spring; autumn-germinated plants have seedlings that established from germination in autumn and continued growing through winter, also known as winter annual plants (Footitt et al., 2014). The autumn-germinated seedlings that successfully overwintered under the low temperature can complete their life cycle together with spring-germinated plants. Autumn-germinated plants and summer annual plants in the Sonoran Desert of the United States were first described in 1936 (Shreve, 1936). Early studies were mainly limited to describing their distribution and morphological characteristics. The bi-seasonal germination phenomenon among ephemeral plants only exists in several families, studied by Chinese scholars, such as Cruciferae, Boraginaceae (Pan, 1995), Papilionatae (Yao and Tan, 2005) and Geraniaceae (Zhang et al., 2007). However, the reproductive characteristics for both autumnand spring-germinated plants are less studied. The bi-seasonal germination phenomenon mainly exists in desert-dwelling ephemeral plants (Zeng et al., 2011). To adapt to the changing environment of a desert, a portion of the seed population germinates in autumn and another portion in spring; this is a result of coevolution between life history strategies and environmental factors (Zhang et al., 2007). The seedlings that germinate in spring may avoid injury and death in winter, and mortality is lower in winter because a large number of autumn-germinated plants choose to flower and fruit early to provide a relative selective advantage (Zeng, 2011). A large number of plant species in the Gurbantuggut Desert in the Junggar Basin of Xinjiang, Northwest China, have the potential to behave as indomitable survivability and ingenious adaptive to the poor environment. To date, there have been many studies on the adaptive strategy of plants in desert ecosystems. The study of bi-seasonal germination has important ecological significance for seedling survival (Gross and Smith, 1991), plant fitness (Masuda and Washitani, 1992), and the expression of life history characteristics. Therefore, it is imperative that the bi-seasonal germination of ephemeral plants in deserts of China should be studied.

Hypecoum erectum L. belongs to Hypecoum in the Papaveraceae family. It behaves as a facultative winter annual plant and is found in the Gurbantunggut Desert of Northern Xinjiang, 
China. This species is one of the most important resources in desert, since it has a high vegetation coverage that can reach $8 \%-10 \%$ in the windy season in May. H. erectum was mainly distributed in the south of the Gurbantunggut Desert in patchy distribution during the field survey from 2015 to 2016. One of the main reasons in its patchy distribution was the high habitat specialization of $H$. erectum (Yang et al., 2015); it forms a large seed bank with a seed behavior that includes germinating in both autumn and spring. With the coming of the dry-hot wind in the Gurbantunggut Desert in the early spring, the smaller spring-germinated plants may face risk of survival and reproduction. By contrast, autumn-germinated plants have larger plant size and better competitive ability than spring-germinated plants. We hypothesized that germination timing (autumn versus spring) would influence plant biomass and reproductive allocation; such that autumn-germinated plants produce more biomass and have a higher reproductive output than spring-germinated plants. To test this hypothesis, the biological characteristics and life history characteristics of $H$. erectum for autumn- and spring-germinated plants were explored to examine their germination strategies and ecological adaptive mechanisms. These results will increase our knowledge of the bi-seasonal germination strategy between autumn- and spring-germinated plants in desert ephemeral plants. Furthermore, studies of the ecological strategy and function of its bi-seasonal germination in the context of desert environments will also be of great value for the phylogenetic study of Papaveraceae plants.

\section{Materials and methods}

\subsection{Study site and species}

All experiments were carried out at the Cainan oilfield on the Gurbantunggut Desert of the Xinjiang Uygur Autonomous Region in Northwest China. According to the data from the Fukang National Field Scientific Observation and Research Station for Desert Ecosystems, the mean temperatures are $14.3^{\circ} \mathrm{C}$ and $-3.3^{\circ} \mathrm{C}$ in April and November, and the extreme temperatures of April and November are $28.4^{\circ} \mathrm{C}$ and $-16.1^{\circ} \mathrm{C}$, respectively (Fig. 1). Annual mean temperature and mean annual precipitation are $6.6^{\circ} \mathrm{C}$ and $150 \mathrm{~mm}$, respectively. The peak period of precipitation is April to July. In the Gurbantunngut Desert, steady snow can create an opportunity in some years for species to germinate in autumn as well as spring season. There is steady snow cover from 100 to $160 \mathrm{~d}$, which is $20-30 \mathrm{~cm}$ thick in winter (Fig. 2). Snowfall accounts for $30 \%$ of the annual precipitation in this region (Zhou et al., 2009). In winter, the mean temperature is $-16.0^{\circ} \mathrm{C}$ and the extreme temperature is $-42.2^{\circ} \mathrm{C}$. It is possible to have $50-60 \mathrm{~d}$ for which the temperature is lower than mean temperature in every year (Zeng et al., 2012). After the snow begins to melt in March or April, this area of the Gurbantunggut Desert becomes dominated by ephemeral species.

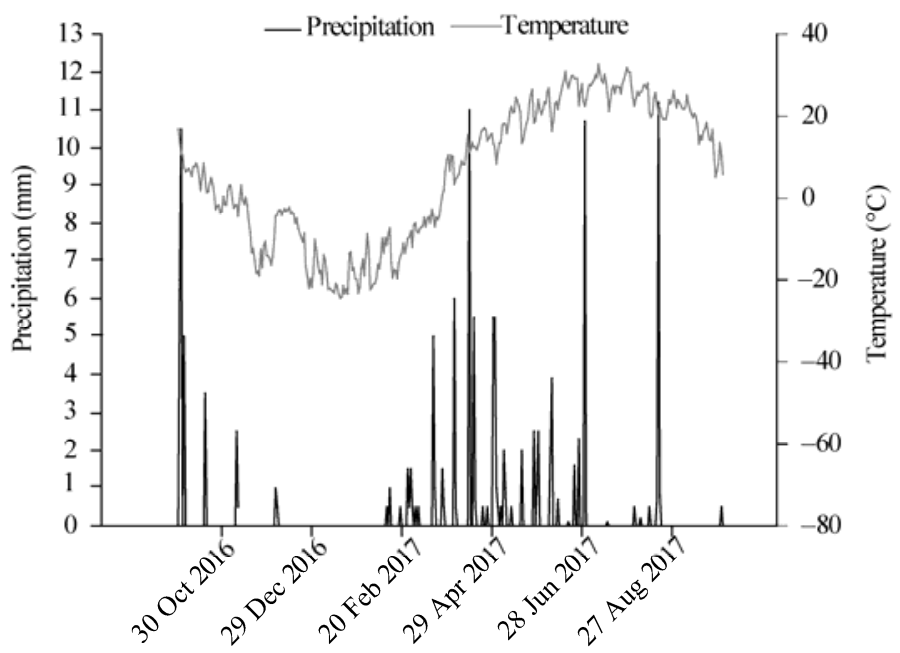


Fig. 1 Precipitation and temperature from 2016 to 2017 in the study area The coverage of ephemeral plants in some areas in the Gurbantunggut Desert can reach up to $40 \%$.

$H$. erectum is a typical desert ephemeral plant and is distributed in the hinterland of the Gurbantunggut Desert in Xinjiang, China. Morphologically, its leaves are basal, lobes are linear with acuminate apex, and the inflorescence type is dichasium cyme. From late October to early November, seeds in the seed bank begin to germinate and grow, to form autumn-germinated seedlings. These survive through the winter under the snow and continue to complete their life cycle after the snow melts in spring of the second year. Spring-germinated plants generally germinate from the end of March to the end of April, which complete their life cycle at the end of May. The field studies and manipulative experiments described in this paper were conducted in 2016 and 2017.

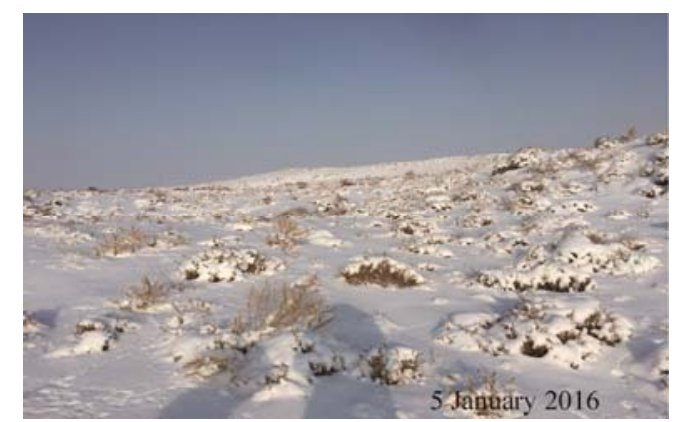

Fig. 2 Scenery of the Gurbantunggut Desert in January 2016

\subsection{Experimental design}

A total of 150 autumn-germinated seedlings of similar size were marked on 2 November 2016. The initial germination time in spring-germinated plants was occurred on 27 March 2017. On 20 April 2017, another 150 spring-germinated seedlings of similar size were selected and marked. The number of autumn- and spring-germinated seedlings surviving from the germination stage to reproduction was counted on 30 May and 10 June in 2017, respectively. The overall experimental design is shown in Figure 3.

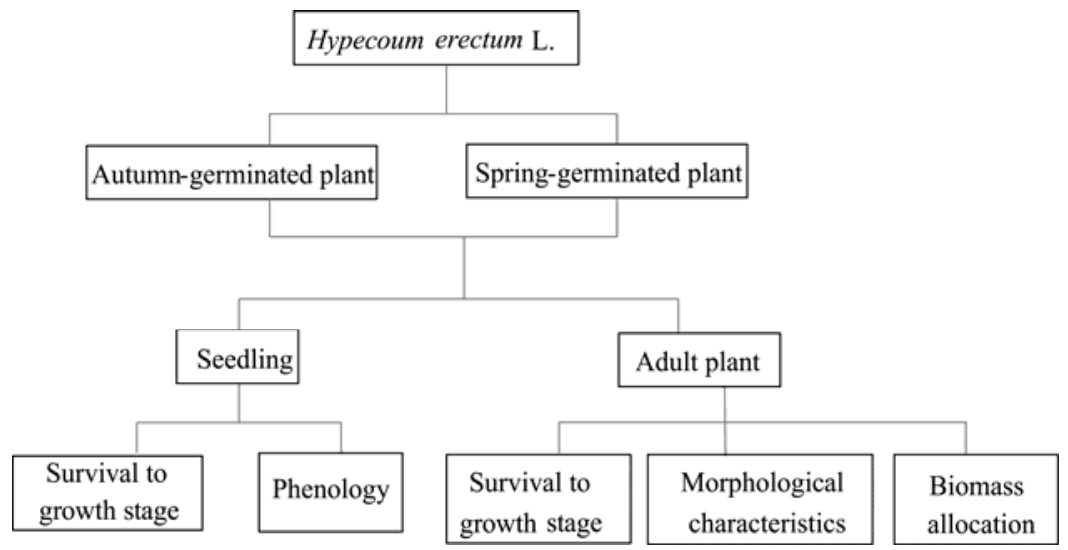

Fig. 3 Experimental design of the study about ecological and biological characteristics and life history strategies between autumn- and spring-geminated plants of H. erectum from 2016 to 2017

\subsection{Phenology observations}

On 15 April 2017, 60 plants (30 autumn-germinated plants+30 spring-germinated plants) were observed for their phenology study. At 1-d intervals from 1 May 2017 to the end of the month, flowering events among individual plants were counted. First flowering date, duration, peak flowering date, and last flowering date were the flowering variables that needed to be observed 
and recorded for plants described earlier. We defined the first flowering date $(25 \%$ of the individual plants in a plot had bloomed), flowering peak (50\% of the individual plants in a plot had bloomed), and the last flowering date (95\% of the individual plants in a plot had finished blooming) according to Wan and Liu (1987).

\subsection{Determination of biomass changes and biomass allocation}

A total of 100 seedlings, i.e., 50 autumn-germinated seedlings marked on 2 November 2016+50 spring-germinated seedlings marked on 15 April 2017, were used to determinate plant biomass changes (i.e., height, crown, principal axis (Fig. 4), and the number of leaves) and biomass allocation in $H$. erectum. The seedling stage was observed at 7-d intervals, while flowing date was observed at 3-d intervals. Fruits produced on inflorescences are not dehiscent at maturity; the plants were excavated to $40 \mathrm{~cm}$ in depth and $40 \mathrm{~cm}$ in diameter (the mean length in roots of $H$. erectum is $30.21( \pm 0.53) \mathrm{cm}$ ) to ensure that they were not damaged and broken, and these whole plants were taken to the laboratory for determination and analysis. In the laboratory, plants were divided into their vegetative organs (i.e., roots, stems, and leaves) and reproductive organs (i.e., fruits). Then they were oven-dried at $80^{\circ} \mathrm{C}$ for $72 \mathrm{~h}$, and their mass was measured on a Sartorius BS201S electronic-balance (Sartorius BS201S, Germany).

Reproductive allocation percentage=reproductive organs biomass (dry weight)/plant total biomass (dry weight) $\times 100 \%$.

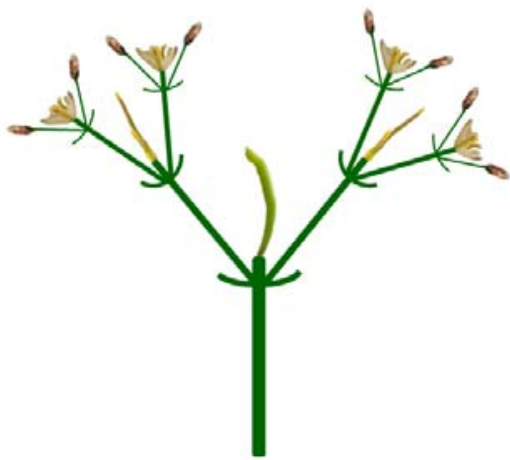

Fig. 4 Diagram of dichasium cyme in $H$. erectum (a principal axis)

\subsection{Statistical analysis}

All data analyses were performed using SPSS 17.0 software and all figures were plotted by Origin 8.5 software. Data were represented as mean \pm standard error. A one-way ANOVA was used to test the differences among height, crown, principal axis, number of leaves and dry weight for the individuals that germinated in two germination seasons. The differences in biomass allocation were compared by paired-sample $t$-test.

\section{Results}

\subsection{Survival rate and phenology}

The survival rates of autumn-germinated plants from germination stage to reproduction stage were $50.21 \%( \pm 0.29 \%)$ and $45.00 \%( \pm 0.58 \%)$, respectively. Autumn-germinated seedlings passed the winter under the snow; half of all seedlings died during this process of overwintering. There was about 5\% mortality from snowmelt to reproduction stage. The survival rate of spring-germinated plants was $46.70 \%( \pm 0.36 \%)$, which was similar to that of autumn-germinated plants $\left(P_{\text {survival rate }}=0.154\right)$.

The results for flowering characteristics of autumn- and spring-germinated plants are shown in Table 1. Flowering duration was $24 \mathrm{~d}$ and $20 \mathrm{~d}$, and the number of flowers per plant was $100( \pm 35)$ and $30( \pm 10)$, in the autumn- and spring-germinated plants, respectively. Autumn-germinated 
plants had an earlier green stage than spring-germinated plants (i.e., leaf-expansion period), and the maturation and withered dates for the whole life history of autumn-germinated plants were significantly earlier than those of spring-germinated plants. Because autumn-germinated plants had a longer post-germination life span than spring-germinated plants, the interval from seedling emergence to the end of the life cycle in autumn-germinated plants was significantly longer than that in spring-germinated plants. During the winter, autumn-germinated plants grew slowly (Fig. 5).

Table 1 Phenology characteristics of the autumn- and spring-geminated plants of H. erectum from 2016 to 2017

\begin{tabular}{lcc}
\hline \multicolumn{1}{c}{ Item } & Autumn-germinated plants & Spring-germinated plants \\
\hline Emergence date & 30 Oct-10 Nov & 30 Mar-5 Apr \\
Green stage date & 3 Apr-23 Apr & 6 Apr-26 Apr \\
First flowering date & 1 May & 8 May \\
Flowering duration (d) & 24 & 20 \\
Peak flowering date & 9 May & 15 May \\
Last flowering date & 24 May & 27 May \\
Maturation date & 15 May-30 May & 23 May-10 Jun \\
Withered date & 25 May-10 Jun & 2 Jun-17 Jun \\
Growth circle (d) & $202-208$ & $53-65$ \\
\hline
\end{tabular}
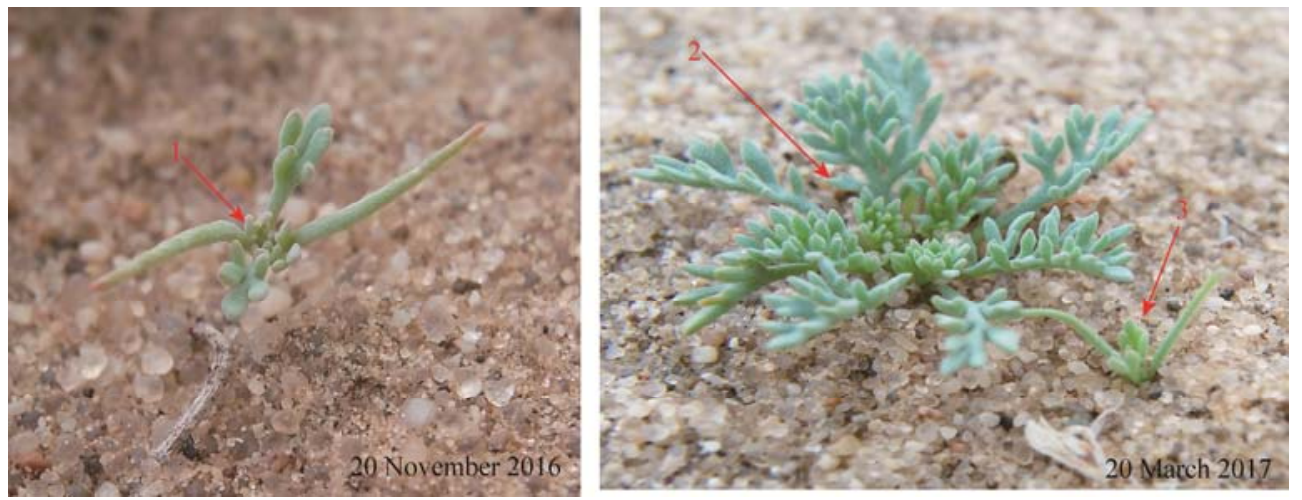

Fig. 5 (1) Autumn-germinated seedling, (2) overwintering plant and (3) spring-germinated seedling from 2016 to 2017

\subsection{Morphological characteristics}

Plant height was quite different between autumn- and spring-germinated plants (Fig. 6a). The average height was $22.88( \pm 1.22)$ and $12.75( \pm 0.98) \mathrm{cm}$ in autumn-germinated plants and spring-germinated plants, respectively, and their maximum heights recorded were 32.25 and 21.11 $\mathrm{cm}$, respectively. The crown of autumn-germinated plants was larger than that of spring-germinated plants (Fig. 6b). Concerning the plant principal axis, the order was autumn-germinated plants>spring-germinated plants (Fig. 6c). Also the growth period and quantity of autumn-germinated plants were significantly earlier and more than those of spring-germinated plants, respectively. In early May, the principal axis quantity of autumn-germinated plants was significantly higher than that of spring-germinated plants, with up to a maximum of 19 and 4 branches, respectively. Similarly, the number of leaves of autumngerminated plants was 27 ( \pm 2 ), which exceeded that of spring-germinated plants (Fig. 6d).

\subsection{Biomass accumulation and allocation}

3.3.1 Relationship between plant size and reproductive biomass

Plant size (i.e., nutritive organ biomass) had a linear positive correlation with reproductive 
biomass, and the latter increased with increasing plant size of $H$. erectum (Fig. 7).
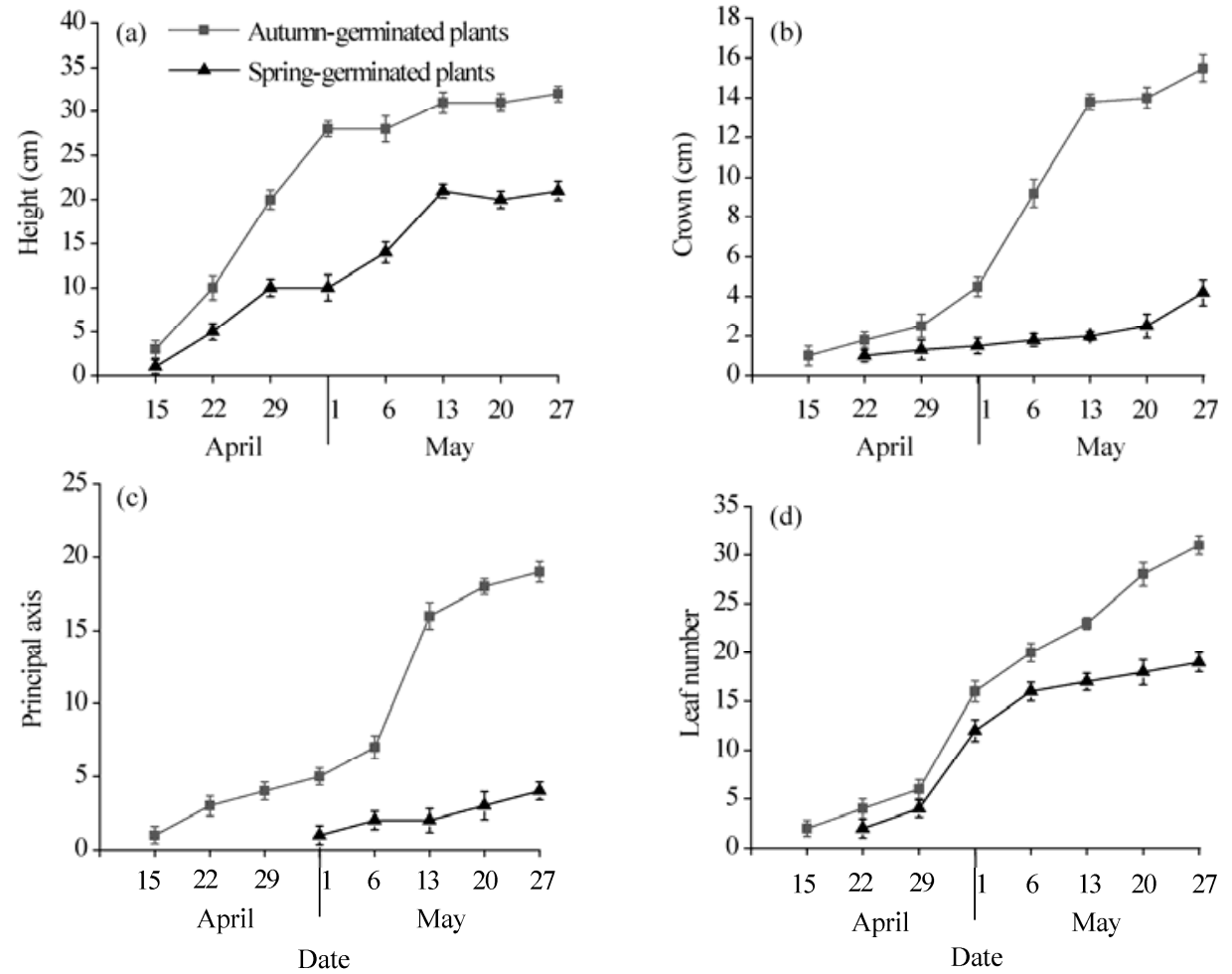

Fig. 6 Height, crown, principal axis and leave number of H. erectum in the autumn- and spring-germinated plants from 2016 to 2017
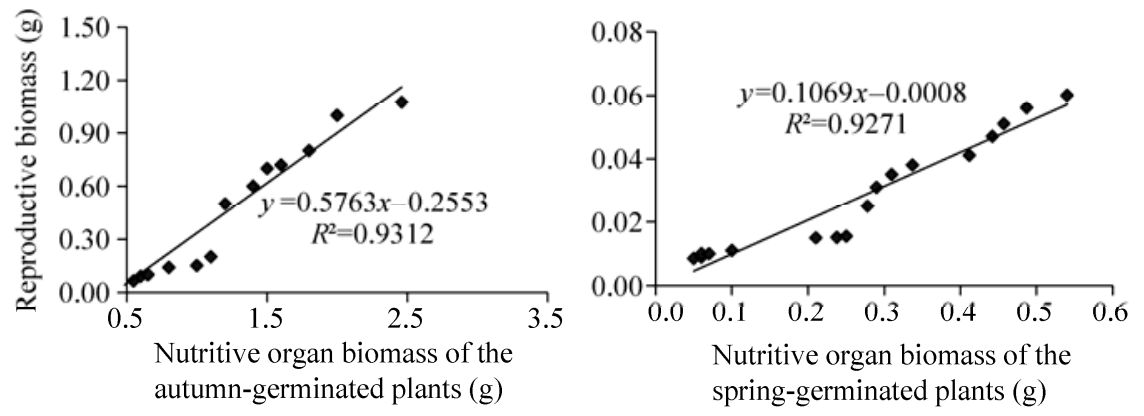

Fig. 7 Relationship between nutritive organ biomass and reproductive biomass of the autumn- and spring-germinated plants from 2016 to 2017

\subsubsection{Relationship between vegetative output and reproductive output}

Total dry mass of $H$. erectum was $3.532( \pm 0.022)$ and $0.551( \pm 0.053) \mathrm{g} /$ plant in autumn-germinated plants and spring-germinated plants, respectively. The vegetative biomass, reproductive biomass, and reproductive allocation percentage of autumn-germinated plants were significantly higher than those of spring-germinated plants $(P<0.01$; Table 2$)$.

\subsubsection{Biomass accumulation and allocation}

The proportion of the biomass for the whole plants in their root, stem, leaf, and fruit parts on the plant maturation date is shown in Figure 8. Allocation to fruits in autumn-germinated plants was significantly higher than that in spring-germinated plants with significant difference $\left(t_{\text {fruit }}=501.500, P_{\text {fruit }}=0.000\right)$. Allocation of biomass to reproduction was $30.24 \%( \pm 2.41 \%)$ and 
$10.12 \%( \pm 0.68 \%)$ in autumn- and spring-germinated plants, respectively.

Table 2 Biomass allocation of the autumn- and spring-geminated plants of $H$. erectum and the influence of germination season on biomass allocation from 2016 to 2017

\begin{tabular}{lccr}
\hline \multicolumn{1}{c}{ Item } & Autumn-germinated plants & Spring-germinated plants & $t$ \\
\hline Vegetative biomass (g) & $2.465 \pm 0.038^{* *}$ & $0.495 \pm 0.042$ & 43.181 \\
Reproductive biomass (g) & $1.068 \pm 0.016^{* *}$ & $0.056 \pm 0.005$ & 148.063 \\
Biomass allocation (g) & $0.302 \pm 0.007^{* *}$ & $0.102 \pm 0.002$ & 53.624 \\
\hline
\end{tabular}

Note: ${ }^{* *}$ indicates significance at $P<0.01$ level. Mean \pm SE; $n=20$.

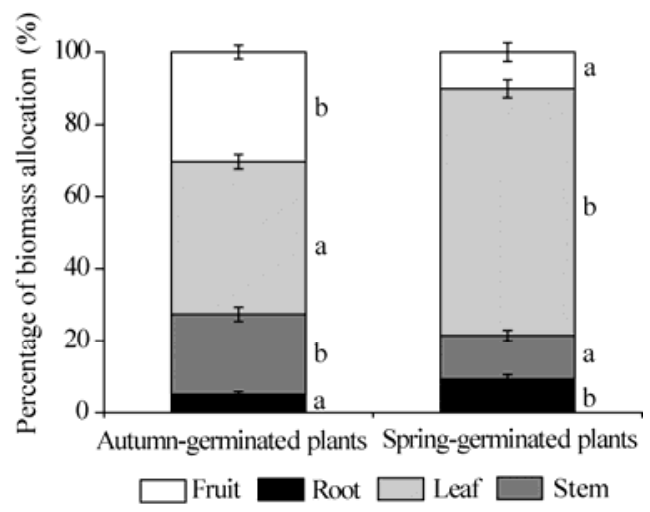

Fig. 8 Percentage of biomass allocation of the autumn- and spring-germinated plants of H. erectum from 2016 to 2017. Different lowercase letters indicate significance between autumn- and spring-germinated plants at $P<0.05$ level. Bars indicate standard errors.

\section{Discussion}

Papaveraceae is an important constituent of desert ecosystem and has a vital role in stabilizing the desert ecosystem and enriching species diversity. This research may provide references for the study of the bi-seasonal germination phenomenon in Papaveraceae. Life history traits of $H$. erectum greatly differed between plants that germinated in autumn and spring. Thus, we hypothesized that germination season would affect the plant biomass (root, stem, leaf, and fruit) and reproduction allocation. Furthermore, autumn-germinated plants produced more biomass and had a higher reproductive output than spring-germinated plants.

\subsection{Relationship between reproductive allocation and vegetative biomass in the autumn- and spring-germinated plants}

Reproductive strategy for plant is to adjust resource allocation model to get the best allocation strategy, then adapting the changing environment. Hence, it is a way to effectively improve plant fitness (Fabbro and Körner, 2004). Studies of plant size and reproductive allocation often show that seed yield is positively correlated with plant size in annual plants. Seed yield increases with increasing plant size (Klinkhamer et al., 1997). Susko and Lovett-Doust (2000) researched the life cycle of Alliaria petiolate, and the results showed that when its available resources were reduced, the possibility to gain parent resources and augment their reproductive output were greater in plants with a larger plant size than those with a smaller plant size. There are very significant differences among plant size, reproductive output, and reproductive allocation between autumnand spring-germinated plants in $H$. erectum. During the life cycle, reproductive biomass is produced by per-unit-vegetative growth biomass, but there is a close coordination with plant size (Yao, 2005). Herrera (1991) found that the reproductive capacity of most plants depends more on plant size than on their age. Timing of germination was earlier (autumn- >spring-germinated plants) in Trigonella cancellata, whereas the percent of dry mass allocated to reproduction, and the ability to resist drought and cold-hardiness were all higher in autumn-germinated plants than 
in spring-germinated plants (Yao and Tan, 2005). We speculated that autumn-germinated plants have a 5-month longer post-germination life-span than spring-germinated plants in $H$. erectum. Therefore, autumn-germinated plants flowered, matured and withered 7-8 d earlier than spring-germinated plants. Autumn-germinated plants were taller and their crowns were wider than spring-germinated plants. The larger size of autumn-germinated plants suggests that they would be adaptable in the Gurbantunggut Desert where drought, high temperatures, and windy conditions are often common in spring. Resources are limited in the Gurbantunggut Desert and competition is infinite. Therefore, autumn-germinated plant has temporal and resource advantages which reduce the high mortality risk of $H$. erectum.

The reproductive allocation of plant is the result of life history evolution, which is an adaptation to the current environment (Sawrey, 2013). In nature, annual plants are favored to allocate a greater proportion of their resources to reproductive structures, which can reach up to $20 \%-40 \%$, being much higher than that of perennial plants $(0 \%-20 \%$; Silvertown and Charlesworth, 1993). Plants accumulate resources and allocate them for the purposes of survival, growth, reproduction, and defense (Rameau and Gouyon, 1991). Throughout the growing season, the available resources in the environment vary, which further improve the plant fitness by adjusting the resource allocation rate between growth and reproduction; hence, the allocation for production represents a way to effectively adapt to recurring changes (Fabbro and Körner, 2004). We speculated that the post-germination life history characteristics of $H$. erectum significantly differed between autumn- and spring-germinated plants. In this study, autumn- and spring-germinated plants respectively allocated $30.24 \%( \pm 2.41 \%)$ and $10.12 \%( \pm 0.68 \%)$ of their dry mass to reproduction. During plant growth and development, autumn-germinated plants are tended to have a higher reproductive allocation and able to ensure the production of seed. This is beneficial for successful reproduction in the extreme desert environment.

\subsection{Relationship between germination timing and plant crown}

Windy conditions prevail from April to September in the Gurbantunggut Desert, resulting in frequent sandstorms (Yang et al., 2005). Vegetation cover improves soil conservation by reducing wind speed and the frequency of sandstorms (Qian et al., 2004). Many studies have shown that wind erosion and desertification can be reduced by increasing vegetative coverage (Wolfe and Nickling, 1993; Dong et al., 1996). Vegetation coverage has also long been used as an index to evaluate soil and water relations.

In the same plant population, vegetation coverage increases as plant crown size increases (Rittenhouse and Sneva, 1977). In this study, the crown and the vegetative coverage of autumn-germinated plants were significantly greater than those of spring-germinated plants. This means that autumn-germinated $H$. erectum has a greater ability than spring-germinated plants to fix sand and conserve soil and water. Therefore, autumn-germinated $H$. erectum is important for maintaining the stability of the desert ecological system.

\subsection{Germination strategy and adaptive significance of bi-seasonal germination}

Seed germination is an important growth phase in plant life cycle. Germination time strongly influences the competitive ability, mortality and reproductive output of plants (Gonzalezastorga and Nunezfarfan, 2000; Donohue et al., 2010). Hot and dry conditions, strong winds, and other unfavorable environmental conditions drive evolution and plant development in desert ecosystems. Plants adapt to harsh environments by choosing the optimal time and place to germinate (Venable, 1985). A portion of seeds germinated in one season whereas another portion did in multiple seasons, thus avoiding the negative effects of plant density (Cheplick, 1992; Sadeh et al., 2009). Yao and Tan (2005) researched four ephemeral species of Trigonella in the Junggar Desert in Northwest China. The results showed that different germination time allowed the plants to avoid the effects of harsh environmental conditions on reproductive success and also to reduce competition among sibling seedlings. $H$. erectum is a typical desert ephemeral plant with two germination seasons. Fewer species and less vegetative coverage were distributed in autumn than in spring in the desert. Therefore, the autumn-germinated seedlings of $H$. erectum had an 
advantage in avoiding competition between annual and perennial herbs that had longer periods of vegetative growth. However, only half of the autumn-germinated $H$. erectum seedlings survived in cold winter. Many spring-germinated seedlings were needed to grow and reproduce to ensure the survival of the population. The spring-germinated $H$. erectum seeds grew and matured rapidly, thus avoiding the hot dry summer.

On a community level, the multiple seasons in germination strategy among plants can contribute to peaceful coexistence, because this way can allow for provisional partitioning of environmental resources and allocate to plants which grow in different seasons (Ellner, 1987; Chesson, 2000). Bi-seasonal germination of ephemeral plants increases their vegetative coverage and improves their ability to compete with other species and also allows plants to efficiently utilize environmental resources across time, thus affecting the persistence and enlargement of plant populations (Yao and Tan, 2005). Bi-seasonal germination of $H$. erectum can reduce competition among sibling seedlings, increasing the survival probability of offspring in a temporally heterogeneous environment and allowing plants to successfully establish themselves in an unstable environment. We infer that the bi-seasonal germination strategy of $H$. erectum resulted from long-term adaptation to the harsh environment of the Gurbantunggut Desert.

Likely due to the strong interference by the desert road highway, south-to-north water transfers, petroleum exploitation, grazing activities, and harm from rodents (group coverage precentage for Rhombomys opimus holes in the southern Gurbantunggut Desert was 19.4\%), we found that $H$. erectum was growing on the leeward slope on a semi-mobile dune in a patchy distribution. The current habitat for $H$. erectum populations is poor, and its population numbers and sizes are declining, which calls for an urgent protection and restoration of these threatened species (Yang et al., 2015). One major internal factor that threatens the $H$. erectum populations is the low survival of its autumn- and spring-germinated plants. Presently, the main way to rejuvenate its populations is by increasing the total numbers of seedlings that emerge from seed and by improving the seedling survival rate. Protecting the area of existing $H$. erectum populations, as well as preserving its seed bank to ensure a higher germination rate, represent further steps towards conserving this species and restoring its population sizes.

\section{Conclusions}

Seed germination timing occurred in two seasons, one part of seeds geminated in autumn, and another part germinated until the following spring. The interval from seedling emergence to the end of the life cycle was significantly longer in autumn-germinated plants (202-208 d) than in spring-germinated ones (53-65 d). Compared with the morphological characteristics of the spring-germinated plants and autumn-germinated plants, we found that autumn-germinated plants were significantly taller than spring-germinated plants, and the number of leaves was also greater in autumn-germinated plants (27 ( \pm 2$)$ leaves per plant) than in spring-germinated plants $(14( \pm 1)$ leaves per plant). Allocation to fruits in autumn-germinated plants was significantly higher than that in spring-germinated plants, and spring-germinated plants allocated significantly larger proportion of biomass to leaves. We conclude that the bi-seasonal germination is an optimal growth strategy for $H$. erectum.

\section{Acknowledgements}

This work was supported by the National Natural Science Foundation of China (31660061, 31460183, 31200417) and the Corps Scientific Program Project (2015AD023).

\section{References}

Chen Z C, Shi Z Y, Tian C Y, et al. 2008. Diversity and spatial distribution characteristics of ephemeral plants germinated in autumn in the southern edge of Gurbantunggut Desert. Journal of Anhui Agricultural Sciences, 36(5): 2016-2018. (in Chinese)

Cheplick G P. 1992. Sibling competition in plants. Journal of Ecology, 80(3): 567-575. 
Chesson P. 2000. Mechanisms of maintenance of species diversity. Annual Review of Ecology and Systematics, 31(1): 343-366.

Dong Z B, Chen W N, Dong G R, et al. 1996. Influences of vegetation cover on the wind erosion of sandy soil. Acta Scientiae Circumstantiae, 16(4): 437-443. (in Chinese)

Donohue K, de Casas R R, Burghardt L, et al. 2010. Germination, postgermination adaptation, and species ecological ranges. Annual Review of Ecology, Evolution, and Systematics, 41(41): 293-319.

Ellner S. 1987. Alternate plant life history strategies and coexistence in randomly varying environments. Vegetatio, 69(1-3): 199-208.

Fabbro T, Körner C. 2004. Altitudinal differences in flower traits and reproductive allocation. Flora, 199(1): 70-81.

Footitt S, Clay H A, Dent K, et al. 2014. Environment sensing in spring-dispersed seeds of a winter annual Arabidopsis influences the regulation of dormancy to align germination potential with seasonal changes. New Phytologist, 202(3): 929-939.

Gonzálezastorga J, Núñezfarfan J. 2000. Variable demography in relation to germination time in the annual plant Tagetes micrantha Cav. (Asteraceae). Plant Ecology, 151(2): 253-259.

Gross K L, Smith A D. 1991. Seed mass and emergence time effects on performance of Panicum dichotomiflorum Michx. across environments. Oecologia, 87(2): 270-278.

Gutterman Y. 2000. Environmental factors and survival strategies of annual plant species in the Negev Desert, Israel. Plant Species Biology, 15(2): 113-125.

Huang P Y. 2002. Non irrigated vegetation and its restoration in arid areas. Beijing Science Press, 80-81. (in Chinese)

Herrera J. 1991. Allocation of reproductive resources within and among inflorescences of Lavandula stoechas (Lamiaceae). American Journal of Botany, 78(6): 789-794.

Klinkhamer P G L, de Jong T J, Metz H. 1997. Sex and size in cosexual plants. Trends in Ecology \& Evolution, 12(7): $260-265$.

Lambrecht S C, Loik M E, Inouye D W, et al. 2007. Reproductive and physiological responses to simulated climate warming for four subalpine species. New Phytologist, 173(1): 121-134.

Liu X F, Tan D Y. 2007. Diaspore characteristics and dispersal strategies of 24 ephemeral species of Brassicaceae in the Junggar Desert of China. Journal of Plant Ecology, 31(6): 1019-1027. (in Chinese)

Ma S J, Tan D Y. 2007. Phenology and sex expression of Junggar Desert ephemerals Neotorularia korolkovii and Isatis violascens (Brassicaceae). Acta Ecologica Sinica, 27(2): 486-496. (in Chinese)

Masuda M, Washitani I. 1992. Differentiation of spring emerging and autumn emerging ecotypes in Galium spurium L. var. echinospermon. Oecologia, 89(1): 42-46.

Mccauley R A, Allen S D, Breeden M R, et al. 2017. Pollination ecology of the newly described narrow endemic Ipomopsis ramosa (Polemoniaceae) in southwestern Colorado. Phytologia, 99(2): 118-125.

Pan W B. 1995. The ecology of four ephemeral plants. Acta Phytoecologica Sinica, 19(1): 85-91. (in Chinese)

Qian Y B, Wu Z N, Zhang L Y, et al. 2004. Ground-surface conditions resulting in dust storms in the south Junggar Basin. Arid Land Geography, 27(4): 540-542. (in Chinese)

Qiu J, Tan D Y, Fan D Y. 2007. Characteristics of photosynthesis and biomass allocation of spring ephemerals in the Junggar Desert. Journal of Plant Ecology, 31(5): 883-891. (in Chinese)

Rameau C, Gouyon P H. 1991. Resource allocation to growth, reproduction and survival in Gladiolus: The cost of male function. Journal of Evolutionary Biology, 4(2): 291-307.

Rittenhouse L R, Sneva F A. 1977. A technique for estimating big sagebrush production. Journal of Range Management, 30(1): 68-70.

Sadeh A, Guterman H, Gersani M, et al. 2009 Plastic bet-hedging in an amphicarpic annual: an integrated strategy under variable conditions. Evolutionary Ecology, 23(3): 373-388.

Sawrey O R P. 2013. Effect of altitude and co-occurring species on sequential reproductive stages in a grassland harebell. PhD Dissertation. Otago: University of Otago.

Shreve F. 1936. The plant life of the Sonoran Desert. Scientific Monthly, 42(3): 195-213.

Silvertown J, Charlesworth D. 1993. Introduction to Plant Population Biology. Oxford: Blackwell Science Publication, 284-286.

Susko D J, Lovett-Doust L. 2000. Plant-size and fruit-position effects on reproductive allocation in Alliaria petiolata (Brassicaceae). Canadian Journal of Botany, 78(11): 1398-1407.

Tan D Y, Tian Y W, Aihemaiti. 1996a. Microsporogenesis and the formation of malegametophyte on ephemeral plant in Plantago lessingii. Acta Botanica Boreali-Occidentalia Sinica, 16(2): 164-168. (in Chinese)

Tan D Y, Yu X F, Tian Y W. 1996b. Studies on embryology of ephemeral in Koelpinia linearis Pall. Journal of Xinjiang 
Agricultural University, 19(1): 8-14. (in Chinese)

Venable D L. 1985. The evolutionary ecology of seed heteromorphism. American Naturalist, 126(5): 577-595.

Wan M W, Liu X Z. 1987. The Observation Methods of Phenology in China. Beijing Science Press, 56-57. (in Chinese)

Wang X Q, Jiang J, Lei J Q, et al. 2003. The distribution of ephemeral vegetation on the longitudinal dune surface and its stabilization significance in the Gurbantunggut Desert. Acta Geographica Sinica, 58(4): 598-605. (in Chinese)

Went F W. 1948. Ecology of desert plants. I. Observations on germination in the Joshua tree National Monument, California. Ecology, 29(3): 242-253.

Wolfe S A, Nickling W G. 1993. The protective role of sparse vegetation in wind erosion. Progress in Physical Geography, 17(1): 50-68.

Yang G. 1991. The study on anatomy of the vegetative organ in spring ephemeral plants. Beijing: Science Press, 203-211. (in Chinese)

Yang S L, Shi X, Dong J X, et al. 2015. The community characteristics and biological characteristics of psammophytes ephemeral plant Hypecoum erectum L. Acta Botanica Boreali-Occidentalia Sinica, 35(11): 2299-2306. (in Chinese)

Yang S L. 2016. The reproductive ecology of Hypecoum erectum L. (poppy family). PhD Dissertation. Shihezi: Shihezi University. (in Chinese)

Yang X H, Wang Y B, Cui D, et al. 2005. Some issues of engineering geology in Gurbantunggut Desert: as illustration of a water conducting engineering. Hydrogeology and Engineering Geology, 32(3): 23-26.

Yao H. 2005. The reproductive ecology of four ephemeral species of Trigonella. PhD Dissertation. Urumqi: Xinjiang Agricultural University. (in Chinese)

Yao H, Tan D Y. 2005. Size-dependent reproductive output and life-history strategies in four ephemeral species of Trigonella. Journal of Plant Ecology, 29(6): 954-960. (in Chinese)

Zeng X L. 2011. Characters and trend of seeds germinate in autumn in Gurbantuggut Desert, China. PhD Dissertation. Shihezi: Shihezi University. (in Chinese)

Zeng X L, Liu T, Shen X Y, et al. 2011. Environment-dependence of seed germination in autumn in Gurbantunggut Desert. Chinese Journal of Ecology, 30(8): 1604-1611.

Zeng X L, Liu T, Zhang W B, et al. 2012. Variations in groundwater levels and quality and their effects on vegetation in the western Gurbantunggut Desert. Acta Ecologica Sinica, 32(5): 1490-1501. (in Chinese)

Zhang L Y. 2002. The ephemeral plants in Xinjiang I-Unique ecological and biological characteristics. Plants, 1: 4-6.

Zhang T, Sun Y, Tian C Y, et al. 2007. Ecological and biological differences between spring and autumn plants of two desert ephemerals. Journal of Plant Ecology, 31(6): 1174-1180. (in Chinese)

Zhou H F, Li Y, Tang Y, et al. 2009. The characteristics of the snow-cover and-snowmelt water storage in Gurbantunggut Desert. Arid Zone Research, 26(3): 312-317. (in Chinese)

Zhuang Z, Tian Y W. 1990a. A study of morphology of short lived plant Lepidium perfoliatum L. I anatomical structure of the vegetative organ. Journal of Xinjiang Agricultural University, 13 (3): 50-56. (in Chinese)

Zhuang Z, Tian Y W. 1990b. A study of morphology of short lived plant Lepidium perfoliatum L. II anatomical structure of the reproductive organ. Journal of Xinjiang Agricultural University, 13(4): 42-47. (in Chinese) 